Revisión de tema

\title{
Distribución y caracterización molecular de betalactamasas en bacterias Gram negativas en Colombia, 2001-2016
}

\author{
Ana Mercedes Rada ${ }^{1,2}$, Christian Hernández-Gómez³ , Eliana Restrepo¹, María Virginia \\ Villegas ${ }^{3}$ \\ ${ }^{1}$ Grupo de Bacterias y Cáncer, Facultad de Medicina, Universidad de Antioquia, Medellín, Colombia \\ ${ }^{2}$ Grupo de Biociencias, Facultad de Ciencias de la Salud, Institución Universitaria Colegio Mayor \\ de Antioquia, Medellín, Colombia \\ ${ }^{3}$ Grupo de Investigación en Resistencia Antimicrobiana y Epidemiología Hospitalaria, Universidad \\ El Bosque, Bogotá, D.C., Colombia
}

Las betalactamasas, enzimas con capacidad hidrolítica frente a los antibióticos betalactámicos, son responsables del principal mecanismo de resistencia en bacterias Gram negativas; las de mayor impacto clínico y epidemiológico en los hospitales, son las betalactamasas de espectro extendido (BLEE), las de tipo AmpC y las carbapenemasas. El incremento en su frecuencia y su diseminación a nivel mundial ha limitado cada vez más las opciones terapéuticas tanto en infecciones adquiridas en los hospitales como las que se generan en la comunidad.

En Colombia, las redes de vigilancia y los grupos de investigación iniciaron su estudio desde finales de los años 90 y, así, se logró la caracterización molecular de las diferentes variantes; además, se reportó una gran prevalencia y diseminación en los hospitales de mediana y alta complejidad, y se describió el impacto clínico de las infecciones que causan. Dichos estudios han evidenciado el alto grado de endemia de algunas de estas betalactamasas y, en consecuencia, la necesidad de una inmediata implementación de programas para inducir el uso prudente de los antibióticos y de medidas de vigilancia, que permitan controlar y prevenir su diseminación, con el fin de disminuir la morbimortalidad en los pacientes y preservar las opciones terapéuticas disponibles en la actualidad. En esta revisión, se recopiló la información sobre las variantes, la distribución geográfica y la caracterización molecular de las betalactamasas en Colombia, así como los estudios llevados a cabo desde finales de la década de 90 hasta el 2016, lo cual permitió tener un panorama de las betalactamasas que circulan en diferentes regiones, su incremento en el tiempo y sus implicaciones clínicas.

Recibido: 05/03/18

Aceptado: 03/10/18

Publicado: $12 / 10 / 18$

Citación:

Rada AM, Hernández-Gómez C, Restrepo E, Villegas MV. Distribución y caracterización molecular de betalactamasas en bacterias Gram negativas en Colombia, 2001-2016. Biomédica. 2019;39(Supl.1):199-220

https://doi.org/10.7705/biomedica.v39i3.4351

\section{Correspondencia:}

Ana Mercedes Rada, Facultad de Ciencias de la Salud, Institución Universitaria Colegio Mayor de Antioquia, Carrera 78 No 65-46, Medellín, Colombia Teléfono: (574) 4445611

ana.rada@colmayor.edu.co

Contribución de los autores:

Ana Mercedes Rada: diseño del esquema del artículo, búsqueda y organización bibliográfica y elaboración de cuadros y figuras

María Virginia Villegas: diseño del esquema del artículo

Todos los autores participaron en la revisión del tema y en la escritura del manuscrito.

Financiación:

Colciencias - Programa Ciencia Tecnología e Innovación en Salud, código del proyecto: 111556933375

Conflicto de intereses:

Los autores del presente trabajo declaran no tener ningún conflicto de intereses.
Palabras clave: betalactamasas; bacterias Gram negativas; infecciones bacterianas; programas de optimización del uso de los antimicrobianos; Colombia.

\section{Distribution and molecular characterization of beta-lactamases in Gram-negative} bacteria in Colombia, 2001-2016

Beta-lactamases are enzymes with hydrolytic activity over beta-lactam antibiotics and they are the main resistance mechanism in Gram-negative bacteria. Extended-spectrum beta-lactamases (ESBL), AmpC, and carbapenemases have the greatest clinical and epidemiological impact in hospital settings. The increasing frequency and worldwide spread of these enzymes have limited the therapeutic options in hospital-acquired infections and those originating in the community.

In Colombia, surveillance networks and research groups began studying them in the late 90s. Different variants of these enzymes have been molecularly characterized and their high prevalence and dissemination in medium and high complexity hospitals, along with a high clinical impact, have been reported. Furthermore, many studies in Colombia have evidenced high endemicity for some of these beta-lactamases, which requires an urgent implementation of antimicrobial stewardship programs in order to preserve the few therapeutic options and infection control strategies to prevent and limit their dissemination. In this publication, we carried out a review of the different enzyme variants, geographic distribution, and molecular characterization of these beta-lactamases in Colombia. Additionally, we describe the available information in the literature regarding studies conducted between the late 1990s and 2016, which provide an overview of the beta-lactamases circulating in different regions of Colombia, their increase over time, and their clinical implications.

Keywords: Beta-lactamases; Gram-negative bacteria; bacterial infections; antimicrobial stewardship; Colombia.

Las infecciones por bacterias Gram negativas resistentes a múltiples antibióticos, y su elevada frecuencia tanto en hospitales como en la 
comunidad, se ha convertido en un problema de salud pública en el mundo debido a su asociación con hospitalizaciones más prolongadas, mayores tasas de fracasos terapéuticos, aumento de la mortalidad y mayores costos de la atención hospitalaria (1-3).

Estas bacterias tienen diferentes mecanismos de resistencia a los antibióticos betalactámicos, y la producción de betalactamasas es el principal contra la familia de antibióticos más utilizada para combatir las infecciones bacterianas en el mundo (4).

Entre las betalactamasas de mayor impacto clínico, están las de espectro extendido (BLEE), las cuales se han identificado principalmente en Escherichia coli y Klebsiella pneumoniae, y son codificadas por genes cromosómicos o plasmídicos $(5,6)$. Las BLEE se definen como betalactamasas capaces de hidrolizar penicilinas, cefalosporinas de primera y segunda generación, una o más oximino-cefalosporinas (en particular, cefotaxima, ceftriaxona y ceftazidima) y monobactámicos (aztreonam); una de sus características es ser sensibles a los inhibidores de las betalactamasas, como el ácido clavulánico, el sulbactam, el tazobactam y el avibactam $(7,8)$.

Otras enzimas de importancia clínica son las betalactamasas de tipo AmpC, presentes en algunas enterobacterias y en bacterias Gram negativas no fermentadoras. Estas pueden ser codificadas por genes cromosómicos y presentarse de forma constitutiva o inducible, o ser adquiridas a través de plásmidos. Las enzimas AmpC son capaces de hidrolizar cefalosporinas de tercera generación y cefamicinas, y se diferencian de las BLEE en que no son sensibles a los inhibidores de las betalactamasas (9).

Por último, las betalactamasas de tipo carbapenemasas se han identificado principalmente en Enterobacteriaceae, en Acinetobacter baumannii y en Pseudomonas aeruginosa; su codificación puede ser cromosómica o generarse en genes asociados con varios elementos móviles, como los transposones, los integrones y una variedad de plásmidos, lo que permite su rápida diseminación entre las especies y dentro de ellas. Las carbapenemasas tienen un mayor espectro hidrolítico frente a casi todos los antibióticos betalactámicos, incluidos los carbapenémicos (10).

Los reportes sobre la difusión de las betalactamasas se comenzaron a conocer en Latinoamérica a partir de 1990, específicamente sobre las BLEE en enterobacterias, y algunas de las enzimas tuvieron su origen en este continente. Por otro lado, la aparición y la diseminación de las carbapenemasas en las enterobacterias, en Pseudomonas spp. y en Acinetobacter spp., dejan pocas opciones terapéuticas debido a la multirresistencia que confieren. El aumento de la frecuencia de los reportes de carbapenemasas en la región, sugiere que se han propagado con éxito y que, incluso, se han hecho endémicas en algunos países (11-13).

En Colombia, los reportes de resistencia se iniciaron a finales de los años noventa, cuando en diversos estudios se demostró un aumento de la frecuencia y la expresión de diferentes tipos de BLEE en K. pneumoniae y E. coli (14). Posteriormente, se identificaron diferentes clases de carbapenemasas en enterobacterias y bacterias Gram negativas no fermentadoras que, con el tiempo, se diseminaron $(15,16)$.

El panorama de la resistencia de las bacterias Gram negativas en Colombia es complejo. Gracias a los múltiples estudios de caracterización 
microbiológica y molecular II vevados a cabo por diferentes grupos de vigilancia e investigación del país, se ha logrado conocer la prevalencia, las variantes, la distribución y las implicaciones clínicas de las betalactamasas en los hospitales de diferentes ciudades del país.

El propósito de esta revisión de tema fue recopilar la información disponible en la literatura sobre las diferentes clases y tipos de betalactamasas identificadas en bacterias Gram negativas, su incremento en el tiempo, su diseminación y su actual distribución geográfica en Colombia. Para ello, se hizo una búsqueda bibliográfica en las bases de datos PubMed, SciELO y Google Scholar, y se seleccionaron artículos en español e inglés publicados entre 2001 y 2016.

\section{Clasificación de las betalactamasas}

La resistencia a los antibióticos de las bacterias Gram negativas se produce mediante diversos mecanismos, entre los que se pueden mencionar la alteración del sitio blanco de ciertos antibióticos (17), el incremento de la expresión de los sistemas de eflujo (18), la alteración de la permeabilidad de la membrana externa por pérdida de porinas (19) y la producción de enzimas que inactivan los antibióticos, de las cuales las betalactamasas son las más prevalentes (7).

Estas enzimas escinden el enlace amida en el anillo beta-lactámico y se consideran el principal mecanismo de resistencia a la familia de antibióticos betalactámicos (20). Su clasificación se ha basado, tradicionalmente, en su estructura primaria o en sus características funcionales. Por un lado, Ambler las agrupa en cuatro clases moleculares ( $A$ a $D)$ con base en la secuencia de aminoácidos (21) y, por el otro, Busch las clasifica en grupos funcionales con base en la inhibición de clases específicas de betalactámicos y en las propiedades de inactivación de los inhibidores de betalactamasas (22).

Entre los grupos funcionales, se encuentra el grupo 1, en el que se ubican las cefalosporinasas de clase molecular $C(21,22)$, las cuales son activas contra las cefalosporinas de tercera generación y cefamicinas, como el cefoxitin. Asimismo, usualmente son resistentes a la acción inhibidora del ácido clavulánico y del sulbactam, y poseen una gran afinidad frente al aztreonam $(23,24)$.

El grupo 2, o de clases moleculares A y D $(21,22)$, incluye las serinbetalactamasas y múltiples subgrupos, de los cuales los de mayor importancia clínica son dos subgrupos de la clase A: las betalactamasas de espectro extendido, que hidrolizan cefalosporinas de amplio espectro y antibióticos monobactámicos, y son inhibidas por el ácido clavulánico, y las serin-carbapenemasas, con capacidad de hidrolizar toda clase de betalactámicos (25). Las de clase D poseen propiedades de hidrólisis frente a los carbapenémicos (26).

Por último, las betalactamasas que requieren de iones divalentes de cinc, se clasifican en el grupo 3 como metalo-betalactamasas de clase molecular $B(21,22)$ y se diferenciaron inicialmente por su habilidad para hidrolizar carbapenémicos, en contraste con su poca afinidad o capacidad hidrolítica frente a los monobactámicos; además, no son inhibidas por el ácido clavulánico o el tazobactam, pero sí por quelantes de iones de metal como el ácido etilen-diamino-tetraacético o EDTA (27). 


\section{Betalactamasas de espectro extendido en Colombia}

Desde el momento en que se detectaron los primeros casos de infecciones por enterobacterias productoras de BLEE en los hospitales latinoamericanos, se ha observado un aumento constante de la prevalencia y del número de estas enzimas, hasta el punto de considerarse endémica la producción de BLEE en Klebsiella spp. en Latinoamérica, con altas tasas de infecciones asociadas a la atención en salud en comparación con las de otras regiones del mundo (11).

La expansión de las BLEE se ha dado rápidamente, en especial las del tipo CTX-M, favorecida por la transferencia horizontal de plásmidos y clones exitosos (11). En Colombia, el panorama no difiere del mundial y en diversos estudios se ha evidenciado la tendencia al aumento de la expresión de CTX-M y su circulación estable, con la expresión simultánea de enzimas de tipo SHV y TEM (14).

\section{Enzimas TEM y SHV}

Las betalactamasas de espectro extendido de tipo temoniera (TEM) y la variable de sulfhidrilo (SHV), se derivaron de la sustitución de aminoácidos del grupo de penicilinasas $2 b$. Las BLEE de tipo TEM se derivaron de los grupos TEM-1 y TEM-2 (28), y las de tipo SHV se derivaron del SHV-1 (29). Son capaces de hidrolizar antibióticos betalactámicos de espectro extendido y son fuertemente inhibidas por el ácido clavulánico y el tazobactam. Estas enzimas se han encontrado más frecuentemente en K. pneumoniae y E. coli, y son codificadas en diferentes plásmidos asociados con otros genes de resistencia a los antibióticos (30). Actualmente, se han descrito 189 variantes alélicas de tipo SHV y más de 200 de tipo TEM (31).

El primer reporte de la enzima SHV en Suramérica se presentó en aislamientos de K. pneumoniae de Argentina y Chile en 1988 y 1989, donde se identificaron las variantes de tipo SHV-2 y SHV-5 (32), en tanto que el primer reporte de la TEM se presentó en el 2003 en Argentina, donde se detectaron los tipos TEM-10 y TEM-12 en K. pneumoniae (33).

En Colombia, la caracterización de esta familia de enzimas se hizo a partir de aislamientos de K. pneumoniae en 2001 y 2002. La betalactamasa SHV-5 fue la más frecuente, con una posible diseminación por transferencia horizontal de plásmidos de conjugación (34).

En 2004, en el estudio de caracterización epidemiológica y molecular llevado a cabo por Villegas, et al., en ocho hospitales de tercer nivel de diferentes ciudades de Colombia, se encontró una alta prevalencia de diversas BLEE en diferentes cepas de E. coli y K. pneumoniae, con tasas similares a las reportadas en otros países latinoamericanos. Además, se detectó un alto nivel de resistencia simultánea a otra clase de antibióticos, lo que sugiere la presencia de otros posibles mecanismos de resistencia (35).

En los estudios posteriores desarrollados en algunas ciudades, se reportaron diversas BLEE de tipo SHV en K. pneumoniae y E. coli, entre ellas, las SHV-5, SHV-2a y SHV-12, además de algunas enzimas no detectadas previamente en el país, como SHV-86 y SHV-27 (3641). Asimismo, este tipo de BLEE se reportó en enterobacterias como Enterobacter cloacae, originadas en hospitales y en la comunidad $(39,42-44)$. Ciertos aislamientos presentaron diferentes perfiles de plásmidos, combinaciones de enzimas y resistencia a otros antibióticos no betalactámicos (cuadro 1) (figura 1). 
Cuadro 1. Betalactamasas reportadas en Colombia, 2001-2016

\begin{tabular}{|c|c|c|c|c|c|c|}
\hline $\begin{array}{l}\text { Familia BLEE/AmpC/ } \\
\text { carbapenemasa }\end{array}$ & Variante de enzima & Bacteria & $\begin{array}{l}\text { Año de recolección } \\
\text { del aislamiento }\end{array}$ & Departamento o ciudad & $\begin{array}{c}\text { Año de } \\
\text { publicación }\end{array}$ & Referencia \\
\hline CTX-M-Grupo 1 & $\begin{array}{l}\text { Variante no } \\
\text { identificada }\end{array}$ & Kpn & $2001-2002$ & Bogotá* $^{*}$ & 2003 & - \\
\hline $\begin{array}{l}\text { TEM } \\
\text { SHV }\end{array}$ & $\begin{array}{l}\text { TEM-1 } \\
\text { SHV-5 }\end{array}$ & Kpn & 2001-2002 & Bogotá & 2004 & 34 \\
\hline $\begin{array}{l}\text { TEM } \\
\text { SHV } \\
\text { CTX-M-Grupo } 1\end{array}$ & $\begin{array}{l}\text { Variante no } \\
\text { identificada }\end{array}$ & $\begin{array}{l}\text { Kpn } \\
\text { Kox } \\
\text { Eco }\end{array}$ & 2002 & Medellín, Cali y Bogotá & 2004 & 35 \\
\hline CTX-M-Grupo 1 & CTX-M-12 & $\begin{array}{l}\text { Kpn } \\
\text { Kox } \\
\text { Eco }\end{array}$ & 2002 & Medellín, Cali y Bogotá & 2004 & 52 \\
\hline $\begin{array}{l}\text { CTX-M-Grupo } 1 \\
\text { CTX-M-Grupo } 2 \\
\text { CTX-M-Grupo } 9\end{array}$ & $\begin{array}{l}\text { Variante no } \\
\text { identificada }\end{array}$ & $\begin{array}{l}\text { Kpn } \\
\text { Kox } \\
\text { Eae } \\
\text { Eco }\end{array}$ & 2004 & Bogotá* & 2004 & - \\
\hline VIM & VIM-8 & Pae & 1999-2003 & Cali & 2004 & 90 \\
\hline VIM & VIM-2 & Pae & 2004 & Barranquilla, Cali y Pereira & 2006 & 16 \\
\hline $\begin{array}{l}\text { TEM } \\
\text { SHV } \\
\text { CTX-M-Grupo } 1\end{array}$ & $\begin{array}{l}\text { Variante no } \\
\text { identificada }\end{array}$ & $\mathrm{ECl}$ & 2003 & Bogotá & 2006 & 43 \\
\hline CTX-M-Grupo 1 & CTX-M-12 & Kpn & 2001 & Bogotá & 2006 & 53 \\
\hline $\begin{array}{l}\text { CTX-M-Grupo } 1 \\
\text { CTX-M-Grupo } 2\end{array}$ & $\begin{array}{l}\text { CTX-M-15 } \\
\text { CTX-M-2 }\end{array}$ & Enterobacteriaceae & 2005 & Bogotá & 2006 & 54 \\
\hline $\begin{array}{l}\text { SHV } \\
\text { KPC }\end{array}$ & KPC-2 & Kpn & 2005 & Medellín & 2006 & 72 \\
\hline Subgrupo OXA-23 & OXA-23 & $A b a$ & 2004-2005 & Bogotá & 2006 & 107 \\
\hline KPC & KPC-2 & $\begin{array}{l}\text { Pae } \\
\text { Cfr }\end{array}$ & 2006 & Medellín & 2007 & 73 \\
\hline $\begin{array}{l}\text { Subgrupo OXA-23 } \\
\text { Subgrupo OXA-51 }\end{array}$ & $\begin{array}{l}\text { OXA-23 } \\
\text { OXA-51 }\end{array}$ & $A b a$ & 2005 & $\begin{array}{l}\text { Cali, Bogotá, Medellín, Pereira, } \\
\text { Bucaramanga y Barranquilla }\end{array}$ & 2007 & 108 \\
\hline $\begin{array}{l}\text { Subgrupo OXA-23 } \\
\text { Subgrupo OXA-51 }\end{array}$ & $\begin{array}{l}\text { OXA-23 } \\
\text { OXA-64 } \\
\text { OXA-69 }\end{array}$ & $A b a$ & 2004 & Bogotá & 2008 & 110 \\
\hline $\begin{array}{l}\text { SHV } \\
\text { CTX-M-Grupo } 1 \\
\text { AmpC }\end{array}$ & $\begin{array}{l}\text { Variante no } \\
\text { identificada }\end{array}$ & Kpn, Eco & $2005-2006$ & $\begin{array}{l}\text { Barranquilla, Montería, } \\
\text { Cartagena y Sincelejo }\end{array}$ & 2009 & 38 \\
\hline CTX-M-Grupo 1 & $\begin{array}{l}\text { CTX-M-1 } \\
\text { CTX-M-12 } \\
\text { CTX-M-12a } \\
\text { CTX-M-15 } \\
\text { CTX-M-60 }\end{array}$ & Enterobacteriaceae & 2004-2005 & Bogotá & 2009 & 56 \\
\hline \multirow[t]{2}{*}{ SHV } & $\begin{array}{l}\text { SHV-2 } \\
\text { SHV-5 }\end{array}$ & Kpn, Eco & $2001-2003$ & Barranquilla y Monteria & 2010 & 36 \\
\hline & $\begin{array}{l}\text { SHV-12 } \\
\text { SHV-86 }\end{array}$ & Kpn & & & & \\
\hline CTX-M-Grupo 1 & CTX-M-12 & Eclo & & & & \\
\hline SHV & $\begin{array}{l}\text { SHV-2 } \\
\text { SHV-12 }\end{array}$ & Kpn & $2003-2005$ & Bogotá & 2011 & 37 \\
\hline CTX-M-Grupo 2 & $\begin{array}{l}\text { SHV-27 } \\
\text { CTX-M-1 } \\
\text { CTX-M-12 } \\
\text { CTX-M-15 } \\
\text { CTX-M-2 }\end{array}$ & & & & & \\
\hline TEM & $\begin{array}{l}\text { TEM-1 } \\
\text { CTX-M-12 }\end{array}$ & Eco & 2010 & Cali & 2011 & 57 \\
\hline CTX-M-Grupo 1 & $\begin{array}{l}\text { CTX-M-12a } \\
\text { CTX-M-15 }\end{array}$ & & & & & \\
\hline KPC & KPC-2 & Pae & $2006-2010$ & $\begin{array}{c}\text { Medellín, Bogotá, Barranquilla, } \\
\text { Cali y Pereira }\end{array}$ & 2011 & 76 \\
\hline KPC & $\begin{array}{l}\text { KPC-2 } \\
\text { KPC-3 }\end{array}$ & Kpn & 2008 & Medellin & 2011 & 80 \\
\hline
\end{tabular}




\begin{tabular}{|c|c|c|c|c|c|c|}
\hline VIM & VIM-24 & Kpn & 2010 & Barranquilla & 2011 & 91 \\
\hline $\begin{array}{l}\text { TEM } \\
\text { SHV } \\
\text { CTX-M-Grupo } 1 \\
\text { KPC }\end{array}$ & $\begin{array}{l}\text { TEM-1 } \\
\text { SHV } 1 \text { ó } 2 \\
\text { SHV-11 } \\
\text { SHV-12 } \\
\text { CTX-M-12 } \\
\text { CTX-M-15 } \\
\text { KPC-2 } \\
\text { KPC-3 }\end{array}$ & $\begin{array}{c}\text { Eclo, Kpn } \\
\text { Kpn } \\
\text { Kpn } \\
\text { Eclo, Kox, Kpn } \\
\text { Eclo, Kox, Kpn, Sma } \\
\text { Kpn } \\
\text { Eclo, Eco, Kpn, Sma } \\
\text { Kpn }\end{array}$ & 2009 & $\begin{array}{l}\text { Medellín, Bogotá, Cali, } \\
\text { Bucaramanga, Ibagué, } \\
\text { Barranquilla y Pereira }\end{array}$ & 2012 & 39 \\
\hline $\begin{array}{l}\text { KPC } \\
\text { VIM }\end{array}$ & $\begin{array}{l}\text { KPC-2 } \\
\text { VIM-2 }\end{array}$ & Pae & 2010 & Cali & 2012 & 92 \\
\hline $\begin{array}{l}\text { Subgrupo OXA-23 } \\
\text { Subgrupo OXA-51 }\end{array}$ & $\begin{array}{l}\text { OXA-23 } \\
\text { OXA-51 }\end{array}$ & $A b a$ & $2005-2007$ & Bogotá & 2012 & 111 \\
\hline $\begin{array}{l}\text { TEM } \\
\text { SHV } \\
\text { CTX-M-Grupo } 1 \\
\text { AmpC } \\
\text { KPC }\end{array}$ & $\begin{array}{l}\text { TEM-1 } \\
\text { SHV-2 } \\
\text { SHV-5 } \\
\text { SHV-12 } \\
\text { CTX-M-15 } \\
\text { CMY-2 } \\
\text { KPC-3 }\end{array}$ & $\begin{array}{l}E c o, K p n \\
K p n \\
E c o \\
K p n, E c o \\
K p n, E c o \\
E c o \\
K p n\end{array}$ & 2011 & 3 ciudades de Colombia & 2013 & 60 \\
\hline NMC & NMC-A & $E C l$ & 2009 & Barranquilla & 2013 & 69 \\
\hline $\mathrm{KPC}$ & KPC-2 & Pae & $2007-2008$ & Montería & 2013 & 77 \\
\hline NDM & NDM-1 & Kpn & 2011 & Bogotá & 2013 & 99 \\
\hline $\begin{array}{l}\text { TEM } \\
\text { SHV } \\
\text { CTX-M-Grupo } 1 \\
\text { CTX-M-Grupo } 2 \\
\text { KPC }\end{array}$ & $\mathrm{KPC}-3$ & Kpn & $2008-2010$ & Bogotá & 2014 & 81 \\
\hline $\mathrm{KPC}$ & & Kpn, Pae & 2009-2010 & $\begin{array}{l}\text { Cali, Medellín, Barranquilla, } \\
\text { Ibagué y Pereira }\end{array}$ & 2014 & 78 \\
\hline IMP & $\begin{array}{l}\text { Variante no } \\
\text { identificada }\end{array}$ & Pre & $2012-2014$ & Bogotá & 2017 & 83 \\
\hline GES & $\begin{array}{l}\text { Variante no } \\
\text { identificada }\end{array}$ & $\begin{array}{c}\text { Citrobacter spp } \\
\text { Enterobacter spp } \\
\text { Pseudomonas spp }\end{array}$ & 2012-2014 & $\begin{array}{l}\text { Antioquia, Huila, Valle del } \\
\text { cauca, Norte del Santander y } \\
\text { Santander } \\
\text { Norte del Santander }\end{array}$ & 2017 & \\
\hline Subgrupo OXA-143 & OXA-143 & Acinetobacter spp. & 2012-2014 & & 2017 & \\
\hline $\begin{array}{l}\mathrm{KPC} \\
\mathrm{VIM}\end{array}$ & $\begin{array}{l}\text { KPC-2 } \\
\text { VIM-2 }\end{array}$ & Pae & $2012-2014$ & Medellín & 2014 & 94 \\
\hline NDM & & $\begin{array}{l}\text { Pre, Mmo, Kpn, } \\
\text { Eco, Aha, Sfo, } \\
\text { Afa }\end{array}$ & 2014 & $\begin{array}{c}\text { Bogotá, Antioquia, } \\
\text { Santander, Valle del Cauca, } \\
\text { Huila y Nariño }\end{array}$ & 2014 & 101 \\
\hline Subgrupo OXA-23 & OXA-23 & $A b a$ & $2009-2012$ & $\begin{array}{c}\text { Medellín, Barranquilla, Bogotá, } \\
\text { Pereira, Ibagué, Neiva, Pasto, } \\
\text { Bucaramanga y Cali }\end{array}$ & 2014 & 112 \\
\hline
\end{tabular}




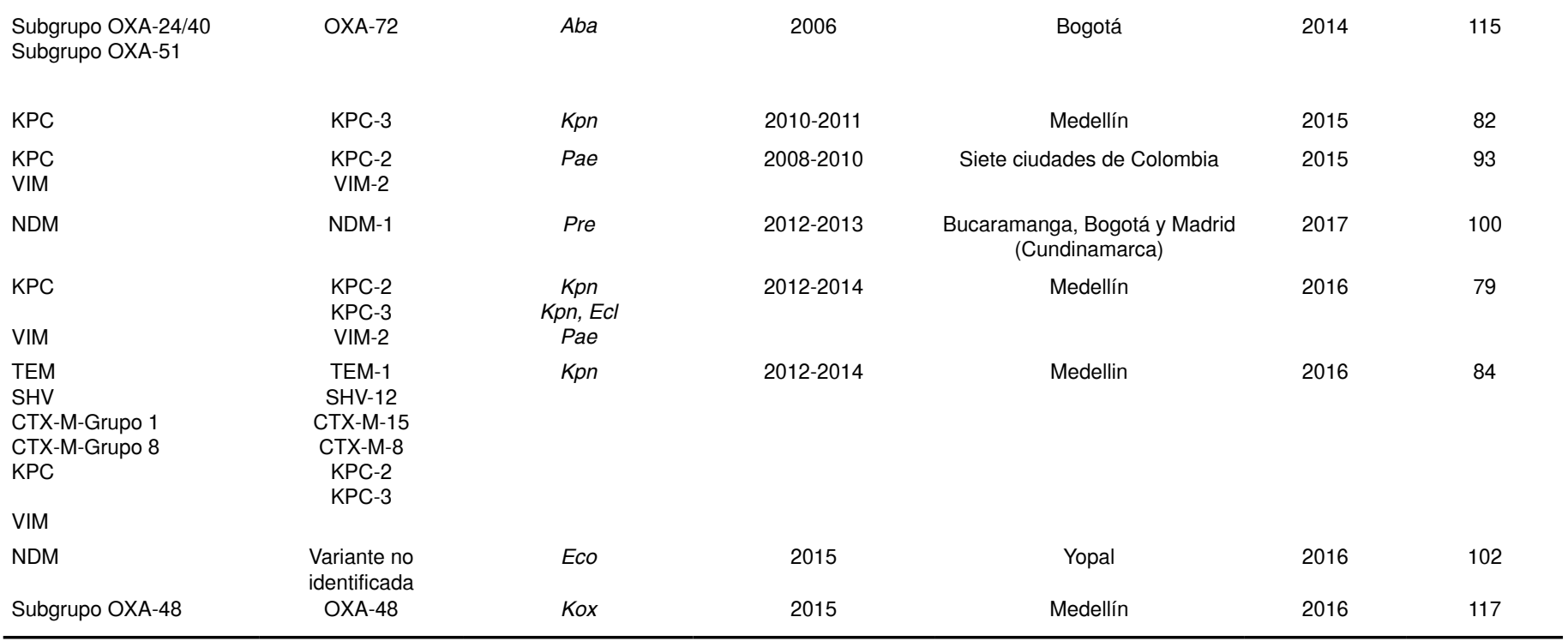

* Resumen de trabajo presentado en congreso.

Aba: A. baumannii; Afa: A. faecalis; Aha: A. haemolyticus; Ano: A. nosocomialis; Api: A. pittii; Cfr: C freundii; Eco: E. coli; Eae: E. aerogenes; Ecl: E. cloacae; Kpn: K. pneumoniae; Kox: K. oxytoca; Mmo: M. morganni; Pae: P. aeruginosa; Pre: P. rettgeri; Sma: S. marcescens; Sfo: S. fonticola

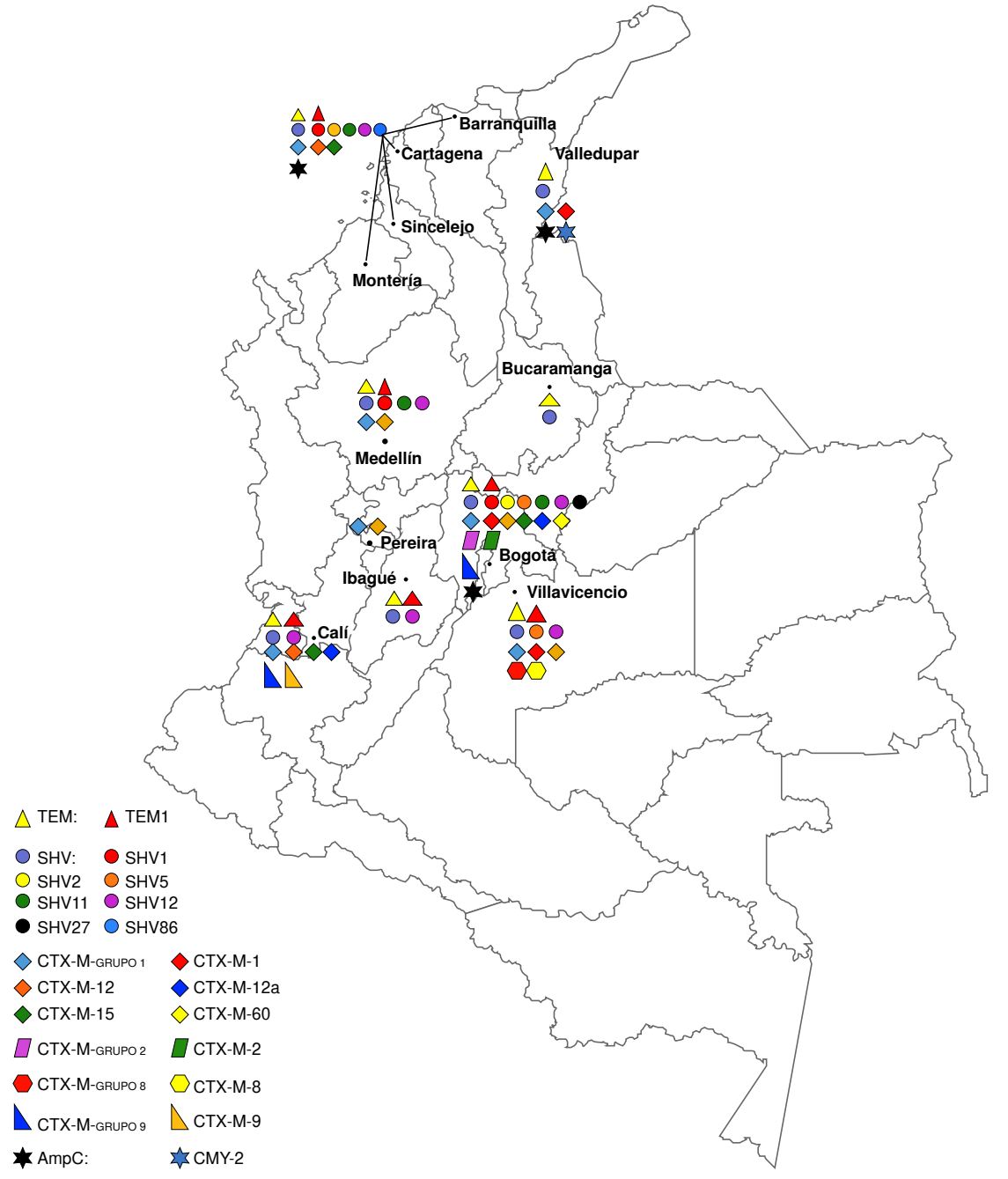

Figura 1. Distribución de BLEE y AmpC en enterobacterias en Colombia 


\section{Enzimas CTX-M}

Las enzimas cefotaximasas (CTX-M) son un tipo de BLEE que no está relacionado con el grupo de las TEM o las SHV. Hidrolizan la cefotaxima y la ceftriaxona con mayor eficacia que a la ceftazidima, y también, hidrolizan la cefepima con gran eficiencia. Se inhiben mejor con el tazobactam que con el ácido clavulánico (45). Estas enzimas de tipo CTX-M han venido reemplazando las variantes TEM y SHV hasta constituirse en el tipo de BLEE más común y de carácter endémico en una amplia área geográfica, que incluye Latinoamérica, Norteamérica, Asia y Europa (46), y se encuentran tanto en el ámbito hospitalario como en la comunidad $(47,48)$.

Hasta la fecha, se han identificado 172 variantes diferentes de las CTX-M (31), divididas en cinco grupos con base en la secuencia de aminoácidos que poseen: CTX-M-1, CTX-M-2, CTX-M-8, CTX-M-9 y CTX-M-25 (49).

Esta familia de enzimas se detectó inicialmente en 1989 en Alemania oriental, en un aislamiento clínico de E. coli (50), aunque fue en Suramérica donde comenzaron a identificarse con gran frecuencia, y es posible que hayan estado en constante circulación desde 1989, como lo sugieren Radice, et al. (51).

El primer informe de cefotaximasas del grupo CTX-M-1 en Colombia, se dio a conocer en el VI Congreso de Enfermedades Infecciosas (Cartagena, 2003). Posteriormente, se reportó la presencia del gen bla- ${ }_{C T X-M 12}$ en uno de siete aislamientos clínicos de K. pneumoniae recolectados en 2002 (52). En los estudios posteriores en diferentes ciudades del país, se registró una alta prevalencia de la enzima CTX-M-12 en cepas de $K$. pneumoniae causantes de infecciones hospitalarias y se encontró, además, en otro tipo de enterobacterias como E. coli y K. oxytoca $(36-38,53,54)$ (Mantilla JR, Valenzuela EM, González EB, Méndez EM, Leal AL, Sierra P, et al. Alta prevalencia de cefotaximasas del grupo CTX-M-1 en Enterobacteriaceae, asociadas a infección intrahospitalaria en Bogotá. Resumen, IV Encuentro Nacional de Investigación en Enfermedades Infecciosas. Infectio.

2004;8:143). Celis, et al., sugirieron que la presencia de este gen, el bla${ }_{C T X-M 12}$, en plásmidos de conjugación de alto peso molecular, fue la causa de su amplia diseminación entre enterobacterias causantes de infecciones hospitalarias en diferentes regiones del país (55).

Otras cefotaximasas reportadas en E. cloacae y K. pneumoniae fueron la CTX-M-12a y la CTX-M-15, así como una nueva variante la CTX-M-60, específicamente en $K$. pneumoniae (56), detectadas tanto en aislamientos hospitalarios como de la comunidad. Asimismo, se identificaron la CTX-M del grupo 8 (41) y la CTX-M del grupo 9 (44), con lo cual se demostró la diversidad y la evolución de este tipo de BLEE en el país.

En 2010, se hizo la primera caracterización molecular de cepas de $E$. coli productoras de CTX-M-15 pertenecientes a los clones ST131 y ST405, asociados con infecciones adquiridas en la comunidad (57). El potencial de propagación de estos clones se convirtió en un tema de gran preocupación, ya que existían pocos datos sobre los mecanismos de diseminación y control de bacterias resistentes en la comunidad, lo que incentivó el estudio de la prevalencia, el impacto clínico y los factores de riesgo de infección con este tipo de microorganismos (cuadro 1) (figura 1). 


\section{Betalactamasas de tipo AmpC en Colombia}

Las betalactamasas de espectro extendido de tipo AmpC y de clase molecular $\mathrm{C}$, son activas frente a las penicilinas pero aún más activas frente a las cefalosporinas: pueden hidrolizar oximino-cefalosporinas (ceftazidima, cefotaxima y ceftriaxona), cefamicinas (cefoxitin y cefotetan) y monobactámicos (aztreonam), a excepción de las cefalosporinas de cuarta generación (cefepima, cefpiroma) y los carbapenémicos. Además, son resistentes a la combinación de betalactámicos con inhibidores de betalactamasas, pero son inhibidas por el ácido borónico y la cloxacilina (25).

Comúnmente, son codificadas en el cromosoma de ciertas enterobacterias y bacterias Gram negativas no fermentadoras y, por lo general, se expresan de manera inducible por la exposición a ciertos betalactámicos. Asimismo, hay especies bacterianas con betalactamasas de tipo AmpC de codificación plasmídica, que pueden ser inducibles o no; sin embargo, E. coli presenta un gen ampC cromosómico que se expresa de manera constitutiva, además de los genes ampC transferidos mediante plásmidos desde otros microorganismos $(9,25)$.

Las betalactamasas de tipo AmpC plasmídicas fueron descritas por primera vez en Suramérica, en Argentina, en la década de los 90, en un aislamiento de K. pneumoniae y fueron denominadas como FOX-1 (58). Posteriormente, se informó sobre la betalactamasa AmpC de tipo CMY-2 en K. pneumoniae, Citrobacter koseri y Shigella flexneri (59).

En Colombia, la primera detección fenotípica de betalactamasas de tipo AmpC se hizo en un estudio desarrollado en 2003 en E. cloacae y, de los aislamientos encontrados, 60,7\% presentaron betalactamasa AmpC 'desreprimida' y $32,1 \%$ presentaron su forma inducible. En este estudio, se consideró la dificultad para interpretar la prueba fenotípica para estas enzimas y se sugirió la implementación de técnicas moleculares (43).

Entre 2005 y 2006, en hospitales de ciudades de la región Caribe, se reportó la detección molecular del gen bla $a_{\text {AmpC }}$ en aislamientos de $E$. coli y $K$. pneumoniae productores de BLEE (38), así como la de enzimas AmpC de tipo CMY-2 en E. coli y K. pneumoniae provenientes de pacientes con infección urinaria adquirida en la comunidad $(40,60)$. Uno de los estudios demostró que los aislamientos portadores de betalactamasa AmpC plasmídica de tipo CMY2 no presentaban relación clonal, por lo cual Leal, et al., sugirieron que su aparición era esporádica y probablemente asociada con brotes. Esta enzima se ha descrito en aislamientos de muestras de origen humano, y en otras de animales de granja o domésticos (60) (cuadro 1) (figura 1).

\section{Betalactamasas de tipo carbapenemasas en Colombia}

Las carbapenemasas representan la familia más versátil de betalactamasas, con capacidad de hidrolizar penicilinas, cefalosporinas y carbapenémicos. Los genes que las codifican están localizados en cromosomas y elementos genéticos como los plásmidos, lo que favorece su rápida propagación y la frecuente transferencia de múltiples genes de resistencia a los antibióticos (61). En la última década, se han convertido en una amenaza real para la salud pública a nivel mundial, ya que afectan la última línea terapéutica de betalactámicos disponibles para el tratamiento de infecciones graves por bacterias Gram negativas $(62,63)$. 
Las betalactamasas de tipo carbapenemasas se clasifican en dos grandes grupos según el mecanismo hidrolítico de su sitio activo. El primer grupo de estas betalactamasas lo integran las carbapenemasas que poseen serina y en él se encuentran las carbapenemasas de clase A (serincarbapenemasas), que incluyen las enzimas IMP/NMC, SME, KPC y GES, y las carbapenemasas de clase D (oxacilinasas), que incluyen la enzima OXA. El segundo grupo es el de las carbapenemasas de clase $B$ del grupo de las metalo-betalactamasas, el cual incluye las enzimas IMP, VIM, GIM, SIM y NDM, que necesitan átomos de cinc como cofactor para ejercer su actividad.

\section{Carbapenemasas de clase A}

\section{Enzimas NMC-A}

Las enzimas NMC-A (no metalo-carbapenemasas de clase A) se identificaron en Francia en 1990, en un aislamiento clínico de E. cloacae con resistencia a ampicilina, cefalotina e imipenem, pero con sensibilidad al cefoxitín y a las cefalosporinas de espectro extendido. El gen se codificó en el cromosoma de este microorganismo y difirió de las características fenotípicas de todas las carbapenemasas descritas previamente (64). Posteriormente, en 2003 y 2006 , también se identificó en aislamientos de E. cloacae en Seattle, Washington y Nueva York (65,66), en el 2004 en Argentina (67), y en el 2012 en Finlandia (68).

El primer reporte en Colombia fue en el 2013, en un aislamiento de $E$. cloacae sensible a las cefalosporinas de espectro extendido, y resistente al cefoxitín y a todos los carbapenémicos (69), hallazgo relevante por ser un nuevo mecanismo de resistencia a los carbapenémicos; además, se encontró que la enzima estaba codificada a nivel cromosómico.

\section{Enzimas KPC}

Las enzimas KPC (Klebsiella pneumoniae productora de carbapenemasas) son de la clase molecular A y las más prevalentes a nivel mundial. Hidrolizan eficientemente las penicilinas, las cefalosporinas, los monobactámicos y los carbapenémicos; además, son inhibidas por el ácido borónico y, parcialmente, por los inhibidores de las betalactamasas, como el ácido clavulánico y el tazobactam (61). Actualmente, se reconocen 23 variantes (31).

La primera variante (KPC-1) fue inicialmente descrita en el 2001 en un aislamiento de K. pneumoniae en Carolina del Norte (70). Se diseminó rápidamente mediante plásmidos, y se reportó en otras enterobacterias y en bacterias Gram negativas no fermentadoras (71).

El primer reporte de enzimas KPC en Suramérica lo hicieron Villegas, et al., en el 2005 en Colombia. Estos autores detectaron la variante KPC-2 en dos aislamientos de K. pneumoniae de diferentes hospitales de Medellín (72). Posteriormente, en el 2007, apareció el primer reporte en el mundo de la KPC-2 en P. aeruginosa en esta misma ciudad (73). En el 2008, se caracterizó el transposón Tn4401 de estos aislamientos, y se sugirió que constituía un elemento genético involucrado en la movilización del gen $b / a_{\mathrm{KPC}}$ a plásmidos, con capacidad de desplazar el gen de su posición inicial a varias regiones del elemento móvil (74).

En los estudios posteriores, se pudo demostrar que los aislamientos de $K$. pneumoniae productores de la enzima KPC estaban asociados con un clon mayor de linaje genético ST258 y sus variantes cercanas, lo que sugirió que su propagación era internacional. Además, los genes $b{ }_{\mathrm{KPC}}$ ubicados en el 
transposón Tn4401 estaban presentes en una variedad de plásmidos, lo que facilitó la rápida propagación de la enzima KPC-2 a K. pneumoniae y a otras especies bacterianas (75).

La diseminación de este gen fue reportada en otras especies de enterobacterias y en $P$. aeruginosa en diferentes ciudades del país; el elemento genético móvil, o transposón Tn4401b, se caracterizó en algunas enterobacterias (44), lo que planteaba que había surgido tiempo atrás (39,41,76-79).

Otra variante de la enzima KPC, identificada como la KPC-3 en $K$. pneumoniae, causó un primer brote en Colombia. Se estableció que el paciente índice provenía de Israel, lo que evidenció la propagación intercontinental de K. pneumoniae productora de KPC-3 (80). Después de este reporte, se demostró que los aislamientos relacionados con el caso índice pertenecían al clon ST512, el cual se integra al complejo clonal 258, lo cual es congruente con estudios previos. Otros hallazgos demostraron la diseminación de la enzima KPC-3 perteneciente al clon ST258 $(39,81,82)$ y su circulación por fuera del ambiente hospitalario en pacientes de diferentes ciudades del país (60). Por ello, Colombia es hoy considerada como una región endémica para las enzimas KPC, con una frecuencia que alcanza el 70,3\% en especies de enterobacterias, según lo ha reportado el grupo de vigilancia del Instituto Nacional de Salud (83).

Recientemente, se publicó un informe sobre la diseminación de la resistencia a los carbapenémicos debida a clones heterogéneos de $K$. pneumoniae no pertenecientes al grupo clonal 258 (GC258) en Medellín, y se sugirió que la transferencia horizontal del gen que codifica para las enzimas KPC ha contribuido a la diseminación de la resistencia a carbapenémicos en este lugar (84) (cuadro 1) (figura 2).

\section{Enzimas GES}

Los genes que codifican la familia de las betalactamasas de espectro extendido de Guyana (GES), se han detectado principalmente en integrones de clase 1, localizados en plásmidos y reportados en $P$. aeruginosa, $A$. baumannii y Enterobacteriaceae. La primera enzima GES se detectó en 1998 en un aislamiento de K. pneumoniae (GES-1) en un hospital de Francia y, originalmente, se identificó como integrante de la familia de las BLEE por su espectro de hidrólisis contra penicilinas y cefalosporinas de espectro extendido. Sin embargo, la sustitución de aminoácidos específicos del sitio activo de algunas de las variantes de esta enzima, extendió el espectro de su actividad a los carbapenémicos (61).

Actualmente, se reconocen más de 27 variantes de enzimas GES (31). Estas se han reportado en países latinoamericanos como Brasil (GES-5, GES16), México (GES-5) y Argentina (GES-2), en P. aeruginosa, K. pneumoniae, E. coli y Serratia marcescens (13). En Colombia, el Instituto Nacional de Salud reportó por primera vez las enzimas GES en aislamientos de Citrobacter spp., Enterobacter spp., y Pseudomonas spp., así como la producción simultánea de KPC más GES y de VIM más GES (83) (cuadro 1) (figura 2).

\section{Carbapenemasas de clase B}

\section{Enzimas IMP}

La enzima IMP (betalactamasa de clase B que hidroliza imipenem) fue la primera carbapenemasa detectada de la familia de las metalobetalactamasas en Japón, en un aislamiento clínico de $P$. aeruginosa; fue 

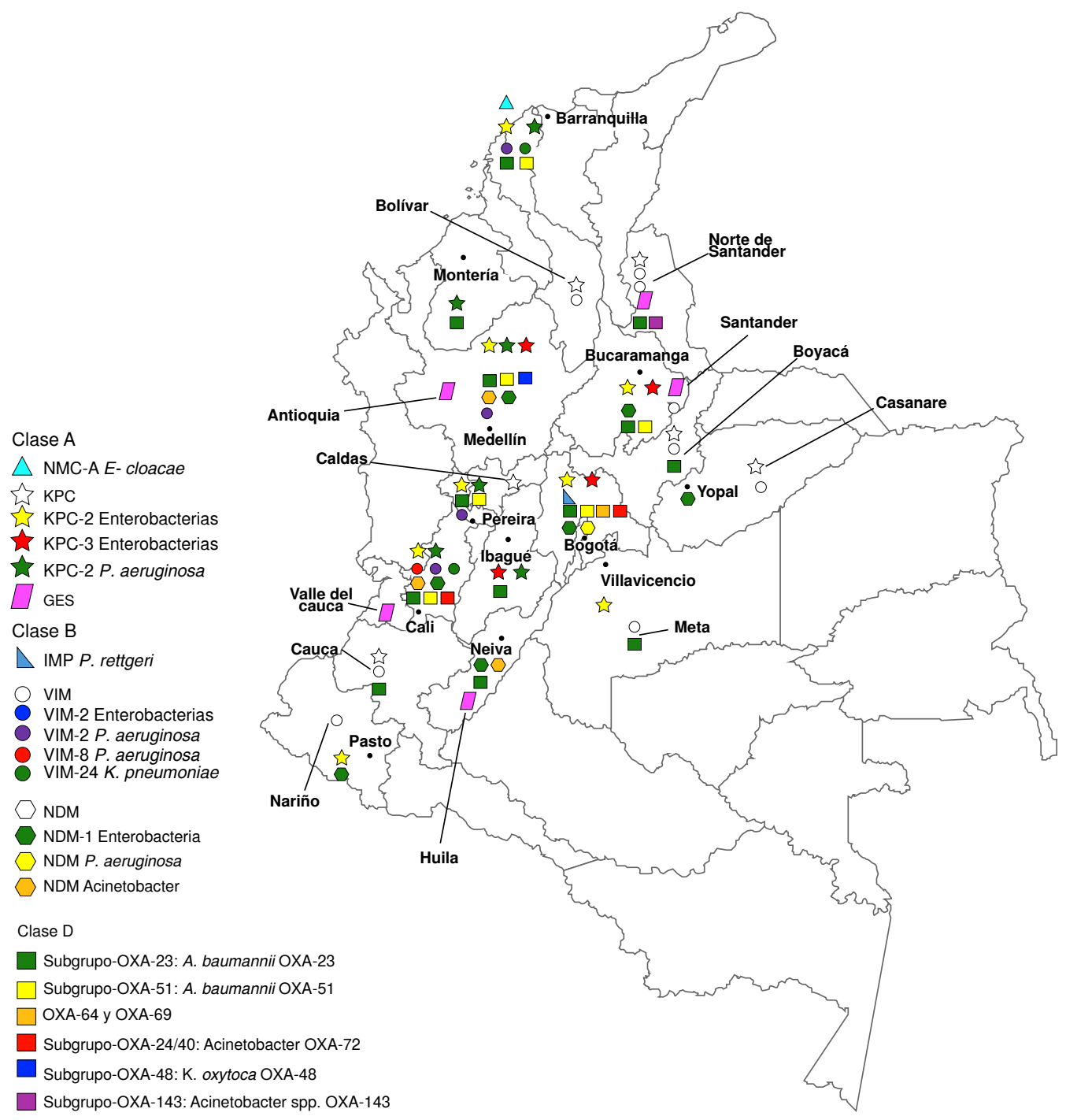

Subgrupo-OXA-23: A. baumannii OXA-23

$\square$ Subgrupo-OXA-51: A. baumannii OXA-51 $\square$ OXA-64 у OXA-69

Subgrupo-OXA-24/40: Acinetobacter OXA-72

Subgrupo-OXA-48: K. oxytoca OXA-48

Subgrupo-OXA-143: Acinetobacter spp. OXA-143

Figura 2. Distribución de carbapenemasas de clase A, B y D en Colombia

identificada en un plásmido de conjugación con un perfil de resistencia a imipenem y a cefalosporinas de espectro extendido (85). Más tarde, en ese mismo país, se identificó en un integrón de $S$. marcescens aislado de un paciente con infección urinaria (86). Las enzimas IMP se han reportado en otros países (61) y ya se han detectado más de 50 variantes (31).

En Latinoamérica, la primera descripción de una enzima IMP (IMP-1) se hizo en un aislamiento de K. pnemoniae multirresistente, tomado de una muestra de sangre de un paciente de 75 años de edad con neumonía asociada a la atención en salud (87). En Colombia, existe un solo reporte de enzimas IMP en un aislamiento de Providencia rettgeri en Bogotá (83) (cuadro 1) (figura 2).

\section{Enzimas VIM}

Entre las carbapenemasas de clase molecular B, se han identificado las enzimas VIM (metalo-betalactamasas codificadas por el integrón verona), las cuales constituyen uno de los más grandes subgrupos de las metalobetalactamasas de subclase molecular B1 (MLB B1) (61), de la cual se han descrito 46 variantes (31). 
La enzima VIM-1 se detectó por primera vez a finales de los años 90 en el norte de Italia, en un aislamiento clínico de $P$. aeruginosa resistente a los carbapenémicos y asociada con un casete genético insertado en un integrón de clase 1 situado en el cromosoma bacteriano (88). La enzima VIM-2, que comparte el $90 \%$ de identidad con la VIM-1 por los aminoácidos que las componen, es la metalo-betalactamasa más extendida en $P$. aeruginosa y ha sido la fuente de múltiples brotes (89). En Latinoamérica, se ha reportado la enzima VIM-2 en Colombia, Chile, Venezuela, Brasil y Argentina, en aislamientos de $P$. aeruginosa (13).

La primera evidencia de este tipo de enzimas en Colombia se dio a conocer en un estudio realizado entre 1997 y 2003 en Cali, en un brote causado por $P$. aeruginosa productora de la VIM-8 (90). Posteriormente, en el 2006, se detectó la variante VIM-2 en $P$. aeruginosa en varias ciudades de Colombia, donde se identificó el gen $b / a_{\mathrm{VIM}-2}$ en algunos clones sobre el mismo integrón y casete genético, así como la presencia de enzimas modificadoras de aminoglucósidos (16).

Una nueva variante es la enzima VIM-24, identificada en un aislamiento de K. pneumoniae en el 2011, documentado como el primer caso de una infección por enterobacterias con metalo-betalactamasas en el país. El gen fue localizado en un integrón de clase 1 y transportado en un plásmido grande, lo que originó la necesidad de estudios posteriores para aclarar su impacto epidemiológico y clínico (91). En un estudio posterior, en el 2013, se detectó la presencia simultánea de la VIM-24 y la KPC-2 en un aislamiento de K. pneumoniae, y su codificación en dos plásmidos diferentes, lo que significó nuevas limitaciones en las opciones terapéuticas (15).

También en Colombia, se describió la presencia de las enzimas VIM-2 y KPC-2 en un mismo aislamiento de $P$. aeruginosa, el cual pertenecía al clon ST111, considerado como un clon exitoso responsable de epidemias en todo el mundo (92). La diseminación de este clon de alto riesgo, se reportó en un estudio del 2014, en el que se incluyeron aislamientos de 16 hospitales de tercer nivel en siete ciudades de Colombia, donde casi todos los aislamientos que portaban el gen $b a_{\mathrm{VIM}-2}$ pertenecían al clon ST111 de $P$. aeruginosa y solo un tipo de secuencia ST235 se asoció con la enzima KPC-2 (93).

Recientemente, en un estudio de aislamientos de $P$. aeruginosa resistente a carbapenémicos en cinco hospitales de tercer nivel de Medellín, se evidenció que la frecuencia de los aislamientos productores de la enzima VIM-2 era similar a la de los aislamientos productores de la KPC-2, lo que sugería una rápida difusión de $P$. aeruginosa productora de estas carbapenemasas. Además, se presentó una estrecha relación genética en los aislamientos dentro de cada hospital, lo que sugería su transmisión intrahospitalaria (94) (cuadro 1) (figura 2).

\section{Enzimas NDM}

Las enzimas NDM (metalo-betalactamasas de tipo Nueva Delhi) confieren una alta resistencia a la mayoría de los antibióticos y tienen un gran efecto negativo en los tratamientos. Esta familia de enzimas NDM pertenece a la clase molecular B y comprende 16 variantes (31). Se reportó por primera vez en el 2008 en Nueva Delhi, en un aislamiento de K. pneumoniae y E. coli recuperado de un paciente sueco. Las enzimas NDM son resistentes a los carbapenémicos y a todos los antibióticos probados, a excepción de la colistina (95). Su diseminación se ha detectado principalmente en enterobacterias y, en menor proporción, en Acinetobacter spp. y $P$. aeruginosa (96). 
Las enzimas NDM se han reportado en diferentes países de Asia, Europa, África y Norteamérica (97). El primer reporte en Latinoamérica fue en el 2008 en Guatemala, en dos aislamientos de K. pneumoniae (98). En Colombia, la enzima NDM-1 se detectó por primera vez en seis aislamientos de $K$. pneumoniae recuperados de un brote que afectó pacientes en una unidad neonatal de Bogotá en el 2011, los cuales pertenecían al clon ST1043 (99).

En los estudios posteriores en diferentes ciudades de Colombia, se demostró la circulación de esta enzima en diferentes bacterias Gram negativas causantes de infecciones asociadas a la atención en salud (100102), lo cual evidencia un grave problema para el país, por su capacidad de diseminación, incluso en la comunidad, y las pocas opciones terapéuticas para tratar a los pacientes infectados (cuadro 1) (figura 2).

\section{Carbapenemasas de clase D}

\section{Enzimas OXA}

Las metalo-betalactamasas de clase $D$ se denominaron enzimas de tipo oxacilinasas (OXA), por su capacidad de hidrolizar la oxacilina y la cloxacilina. Sus genes están integrados en el cromosoma, los plásmidos o los integrones. Además, poseen una gran variabilidad en la secuencia de aminoácidos y se han identificado 498 variantes (31), las cuales se caracterizan porque son poco inhibidas por los inhibidores de las betalactamasas y EDTA (61).

En los años 80, se detectaron aislamientos de $A$. baumannii resistentes a los carbapenémicos debido a la presencia de betalactamasas codificadas en plásmidos y categorizadas como enzimas OXA (103). La primera metalobetalactamasa de tipo OXA se describió en 1993, de un aislamiento de $A$. baumannii con resistencia a múltiples medicamentos, proveniente de un hospital escocés; posteriormente, se denominó OXA-23 y constituyó un nuevo subgrupo de la familia OXA $(104,105)$. Otro subgrupo es el de la OXA51, identificado por primera vez en A. baumannii en Argentina en el 2005, el cual correspondía a enzimas codificadas en el cromosoma y, por lo tanto, presentes de forma natural en este microorganismo (106). Además de estos subgrupos, se han reconocido otros, como los OXA-24/40, OXA-58, OXA-48, OXA-143 y OXA-235, en Latinoamérica y el Caribe (13).

Entre el 2004 y el 2005, en un grupo de aislamientos de $A$. baumannii resistentes a imipenem en una unidad de quemados de Colombia, se detectó el gen bla ${ }_{\mathrm{OXA}-23}$, el cual se identificó como un grupo endémico y se estudió durante los diez meses del estudio (107). En el 2007, Villegas, et al., describieron por primera vez la diseminación de la enzima OXA-23 en Suramérica en 66 aislamientos de $A$. baumannii con multirresistencia, todos productores de carbapenemasas de tipo OXA-51 y, 65 de ellos, productores también del tipo OXA-23. La propagación clonal ocurrió entre hospitales de la misma ciudad y entre hospitales de diferentes ciudades (108). Además, se confirmó la presencia de la secuencia de inserción ISAba1 corriente arriba del bla $a_{\mathrm{OXA}-23}$ y el bla ${ }_{\mathrm{OXA}-51}$, lo que puede afectar la expresión de estos genes $(108,109)$.

En ese mismo año, se demostró la incidencia de $A$. baumannii productora de la metalo-betalactamasa OXA-23, al detectarse un clon en varios servicios hospitalarios, lo que evidenció su dispersión y la causa de un brote que duró 10 meses, así como la presencia de otros tipos de carbapenemasas OXA-64 u OXA-69 (subgrupo OXA-51), lo que permitió sugerir que la resistencia de los 
aislamientos a los carbapenémicos no se ha dado por la expresión conjunta de ambos genes, sino por la sobreexpresión de la carbapenemasa OXA-23 asociada con la presencia de la secuencia de inserción ISAba1 (110).

En estudios posteriores, se demostró la presencia de aislamientos de $A$. baumannii productores de OXA-23 en otras ciudades de Colombia $(111,112)$, y se reportó por primera vez la carbapenemasa OXA-143 (91). Asimismo, en aislamientos de $A$. nosocomialis productores de la carbapenemasa OXA-23 y se reportó por primera vez en aislamientos de $A$. pitti y $A$. baumannii, la presencia de la OXA-58 y la OXA-72 del subgrupo OXA-24/40 (113-115).

La carbapenemasa OXA-48, que hidroliza de forma eficiente penicilinas $y$, debilmente, carbapenémicos, con muy poca actividad contra las cefalosporinas de espectro extendido, se ha reportado principalmente en enterobacterias y se ha detectado cada vez más en muchos países del mundo (116). El primer caso de esta carbapenemasa en Colombia, se registró en el 2016 en un aislamiento de K. oxytoca en un hospital de tercer nivel, en un paciente que había sido hospitalizado previamente en dos instituciones diferentes de Medellín y no había viajado a otros países en el año anterior (117). Sin embargo, hasta el momento no se han reportado otros casos de enterobacterias resistentes a los carbapenémicos que produzcan carbapenemasas de tipo OXA-48 en el país (cuadro 1) (figura 2).

En la figura 3, se resume la evolución de las betalactamasas mencionadas a lo largo del manuscrito según su año de aparición en Colombia.

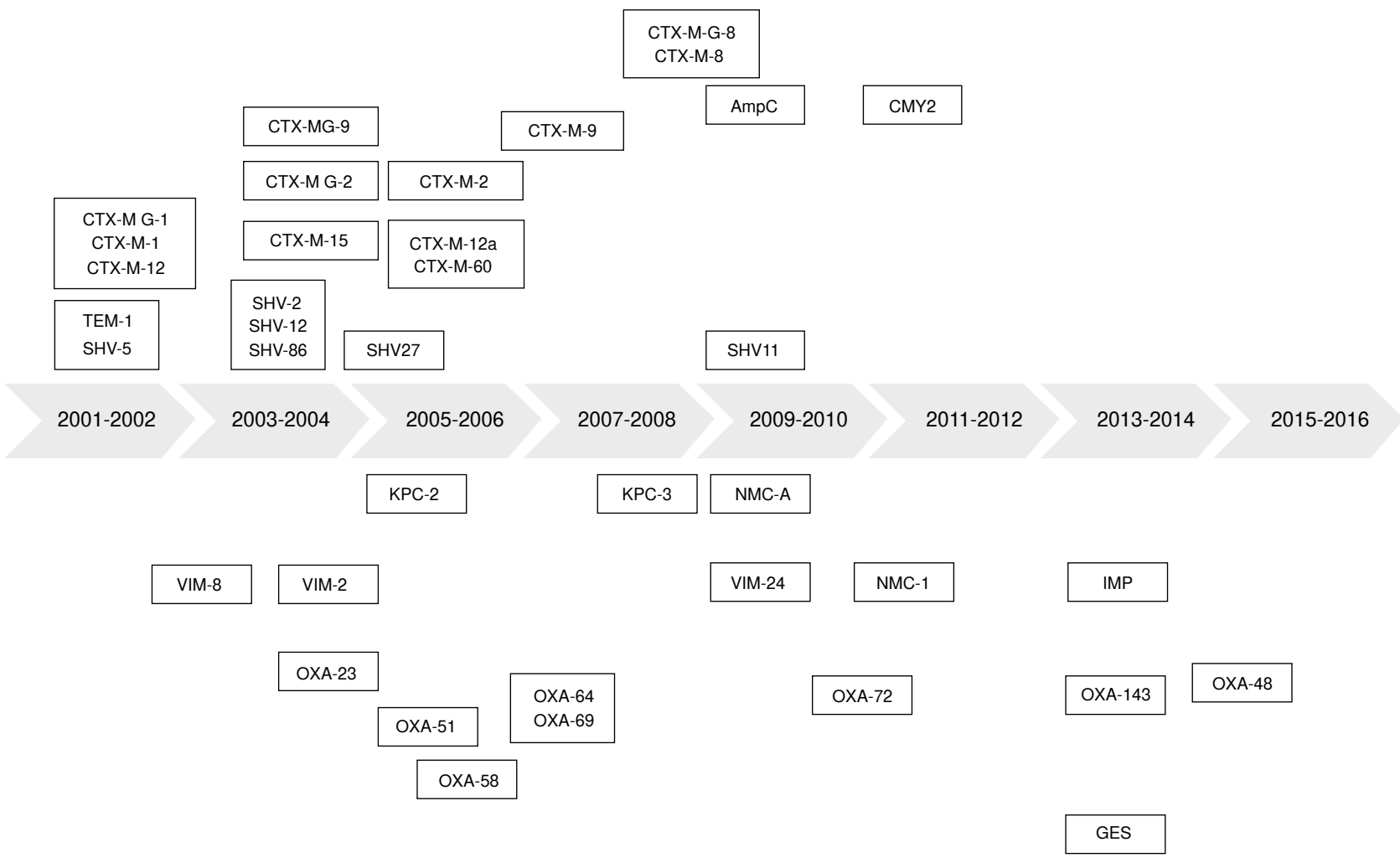

Figura 3. Variantes de BLEE, AmpC y carbapenemasas detectadas en Colombia, 2001-2016 


\section{Conclusión}

Los estudios de caracterización fenotípica y molecular de la resistencia en enterobacterias, Pseudomonas spp. y Acinetobacter spp. llevados a cabo en varias ciudades de Colombia, han permitido conocer el panorama de la resistencia, la aparición, la circulación y la diseminación de diferentes tipos de betalactamasas, como las BLEE, las AmpC y las carbapenemasas, tanto en hospitales como en la comunidad.

Desde los primeros reportes hasta hoy, se han detectado diferentes variantes de estas enzimas y se ha registrado el aumento de su frecuencia, su rápida propagación y la aparición de clones exitosos. Hay una gran preocupación por la diseminación de carbapenemasas mediante elementos móviles, tanto en enterobacterias como en bacterias Gram negativas no fermentadoras, porque esta limita cada vez más las alternativas terapéuticas y convierte a Colombia en un país endémico para estas enzimas.

De ahí, la necesidad de implementar programas para el uso prudente de los antibióticos en los hospitales del país, de hacer seguimiento ampliado en las ciudades para vigilar su presencia en los hospitales, y de fortalecer las estrategias de prevención y control de infecciones. La detección temprana de estos mecanismos de resistencia, posibilita orientar la elección del mejor tratamiento, contener la diseminación de microorganismos resistentes, y disminuir el costo de la atención, la hospitalización y los fracasos terapéuticos.

\section{Referencias}

1. Balsalobre LC, Dropa M, Matté MH. An overview of antimicrobial resistance and its public health significance. Braz J Microbiol. 2014;45:1-5.

https://doi.org/10.1590/S1517-83822014005000033

2. Paterson DL. Impact of antibiotic resistance in gram-negative bacilli on empirical and definitive antibiotic therapy. Clin Infect Dis. 2008;47(Suppl.1):S14-20. https://doi.org/10.1086/590062

3. Tansarli GS, Karageorgopoulos DE, Kapaskelis A, Falagas ME. Impact of antimicrobial multidrug resistance on inpatient care cost: an evaluation of the evidence. Expert Rev Anti Infect Ther. 2013;11:321-31. https://doi.org/10.1586/eri.13.4

4. Shaikh S, Fatima J, Shakil S, Rizvi SM, Kamal MA. Antibiotic resistance and extended spectrum beta-lactamases: Types, epidemiology and treatment. Saudi J Biol Sci. 2015;22:90-101. https://doi.org/10.1016/j.sjbs.2014.08.002

5. Rodríguez I, Thomas K, van Essen A, Schink AK, Day M, Chattaway M, et al. Chromosomal location of blaCTX-M genes in clinical isolates of Escherichia coli from Germany, The Netherlands and the UK. Int J Antimicrob Agents. 2014;43:553-7. https://doi.org/10.1016/j.ijantimicag.2014.02.019

6. Chouchani C, El Salabi A, Marrakchi R, Abouelkacem N, Walsh TR. Occurrence of clinical isolates of Klebsiella pneumoniae harboring chromosomally mediated and plasmid-mediated CTX-M-15 $\beta$-lactamase in a Tunisian hospital. Can J Microbiol. 2012;58:1099-103. https://doi.org/10.1139/w2012-089

7. Ruppé É, Woerther PL, Barbier F. Mechanisms of antimicrobial resistance in Gram-negative bacilli. Ann Intensive Care. 2015;5:61. https://doi.org/10.1186/s13613-015-0061-0

8. Livermore DM, Canton R, Gniadkowski M, Nordmann P, Rossolini GM, Arlet G, et al. CTX-M: Changing the face of ESBLs in Europe. J Antimicrob Chemother. 2007;59:165-74. https://doi.org/10.1093/jac/dkl483

9. Jacoby GA. AmpC beta-lactamases. Clin Microbiol Rev. 2009;22:161-82. https://doi.org/10.1128/CMR.00036-08

10. Diene SM, Rolain JM. Carbapenemase genes and genetic platforms in Gram-negative bacilli: Enterobacteriaceae, Pseudomonas and Acinetobacter species. Clin Microbiol Infect. 2014;20:831-8. https://doi.org/10.1111/1469-0691.12655 
11. Guzmán-Blanco M, Labarca JA, Villegas MV, Gotuzzo E, Latin America Working Group on Bacterial Resistance. Extended spectrum $\beta$-lactamase producers among nosocomial Enterobacteriaceae in Latin America. Braz J Infect Dis. 2014;18:421-33. https://doi.org/10.1016/j.bjid.2013.10.005

12. Casellas JM. Antibacterial drug resistance in Latin America: Consequences for infectious disease control. Rev Panam Salud Pública. 2011;30:519-28. https://doi.org/10.1590/S1020-49892011001200004

13. Escandón-Vargas K, Reyes S, Gutiérrez S, Villegas MV. The epidemiology of carbapenemases in Latin America and the Caribbean. Expert Rev Anti Infect Ther. 2016;20:1-21. https://doi.org/10.1080/14787210.2017.1268918

14. González L, Cortés JA. Systematic review of antimicrobial resistance in Enterobacteriaceae isolates from Colombian hospitals. Biomédica. 2014;34:180-97. https://doi.org/10.7705/biomedica.v34i2.1550

15. Rojas LJ, Mojica MF, Blanco VM, Correa A, Montealegre MC, De la Cadena E, et al. Emergence of Klebsiella pneumoniae coharboring KPC and VIM carbapenemases in Colombia. Antimicrob Agents Chemother. 2013;57:1101-2. https://doi.org/10.1128/AAC.01666-12

16. Villegas M, Lolans K, del Rosario-Olivera M, Suárez CJ, Correa A. Queenan AM, et al. First detection of metallo-beta-lactamase VIM-2 in Pseudomonas aeruginosa isolates from Colombia. Antimicrob Agents Chemother. 2006;50:226-9. https://doi.org/10.1128/AAC.50.1.226-229.2006

17. Ruiz J. Mechanisms of resistance to quinolones: Target alterations, decreased accumulation and DNA gyrase protection. J Antimicrob Chemother. 2003;51:1109-17. https://doi.org/10.1093/jac/dkg222

18. Li XZ, Nikaido H. Efflux-mediated drug resistance in bacteria. Drugs. 2004;64:159-204. https://doi.org/10.2165/00003495-200464020-00004

19. Wolter DJ, Hanson ND, Lister PD. Insertional inactivation of oprD in clinical isolates of Pseudomonas aeruginosa leading to carbapenem resistance. FEMS Microbiol Lett. 2004;236:137-43. https://doi.org/10.1111/j.1574-6968.2004.tb09639.x

20. Jacoby GA, Muñoz-Price LS. The new beta-lactamases. N Engl J Med. 2005;352:380-91 https://doi.org/10.1056/NEJMra041359

21. Ambler RP. The structure of b-lactamases. Philos Trans R Soc Lond B Biol Sci. 1980;289:321-31. https://doi.org/10.1098/rstb.1980.0049

22. Bush K, Jacoby GA, Medeiros AA. A functional classification scheme for b-lactamases and its correlation with molecular structure. Antimicrob Agents Chemother. 1995;39:1211-33. https://doi.org/10.1128/AAC.39.6.1211

23. Bush K. $\beta$-lactamase inhibitors from laboratory to clinic. Clin Microbiol Rev. 1988;1:109-23. https://doi.org/10.1128/CMR.1.1.109

24. Bush K, Freudenberger JS, Sykes RB. Interaction of azthreonam and related monobactams with $\beta$-lactamase from gram-negative bacteria. Antimicrob Agents Chemother. 1982;22:41420. https://doi.org/10.1128/AAC.22.3.414

25. Bush K, Jacoby GA. Updated functional classification of beta-lactamases. Antimicrob Agents Chemother. 2010;54:969-76. https://doi.org/10.1128/AAC.01009-09

26. Walther-Rasmussen J, Hoiby N. OXA-type carbapenemases. J Antimicrob Chemother. 2006;57:373-83. https://doi.org/10.1093/jac/dki482

27. Laraki N, Franceschini N, Rossolini GM, Santucci P, Meunier C, de Pauw E, et al. Biochemical characterization of the Pseudomonas aeruginosa 101/1477 metallo$\beta$-lactamase IMP-1 produced by Escherichia coli. Antimicrob Agents Chemother. 1999;43:902-6. https://doi.org/10.1128/AAC.43.4.902

28. Sougakoff W, Goussard S, Gerbaud G, Courvalin P. Plasmid-mediated resistance to thirdgeneration cephalosporins caused by point mutations in TEM-type penicillinase genes. Rev Infect Dis. 1988;10:879-84.

29. Tzouvelekis LS, Bonomo RA. SHV-type $\beta$-lactamases. Curr Pharm Des. 1999;5:847-64.

30. Bradford PA. Extended-spectrum beta-lactamases in the 21st century: Characterization, epidemiology, and detection of this important resistance threat. Clin Microbiol Rev. 2001;14:933-51. https://doi.org/10.1128/CMR.14.4.933-951.2001 
31. Lahey Clinic. B-lactamase classification and amino acid sequences for TEM, SHV and OXA extended-spectrum and inhibitor resistant enzymes. Fecha de consulta: 15 de febrero de 2017. Disponible en: https://www.lahey.org/studies/

32. Casellas JM, Goldberg M. Incidence of strains producing extended spectrum betalactamases in Argentina. Infection. 1989;17:434-6. https://doi.org/10.1007/BF01645567

33. Paterson DL, Hujer KM, Hujer AM, Yeiser B, Bonomo MD, Rice LB, et al. Extendedspectrum $\beta$-lactamases in Klebsiella pneumoniae bloodstream isolates from seven countries: Dominance and widespread prevalence of SHV- and CTX-M-type $\beta$-lactamases. Antimicrob Agents Chemother. 2003;47:3554-60. https://doi.org/10.1128/AAC.47.11.3554-3560.2003

34. Espinal PA, Mantilla JR, Saavedra CH, Leal AL, Alpuche C, Valenzuela EM. Epidemiología molecular de infección nosocomial por Klebsiella pneumoniae productora de betalactamasas de espectro extendido. Biomédica. 2004;24:252-61. https://doi.org/10.7705/biomedica.v24i3.1271

35. Villegas MA, Correa A, Pérez F, Miranda MC, Zuluaga T, Quinn JP, et al. Prevalence and characterization of extended-spectrum $\beta$-lactamases in Klebsiella pneumoniae and Escherichia coli isolates from Colombian hospitals. Diagn Microbiol Infect Dis. 2004;49:21722. https://doi.org/10.1016/j.diagmicrobio.2004.03.001

36. Espinal P, Garza-Ramos U, Reyna F, Rojas-Moreno T, Sánchez-Pérez A, Carrillo B, et al. Identification of SHV- thype and CTX-M-12 extended- spectrum $\beta$ - lactamases (ESBLs) in multiresistant enterobacteriaceae from Colombian Caribbean hospitals. J Chemother. 2010;22:160-4. https://doi.org/10.1179/joc.2010.22.3.160

37. Pulido I, Mantilla J, Valenzuela E, Reguero M, González E. Distribución de genes codificadores de $\beta$-lactamasas de espectro extendido en aislamientos de Klebsiella pneumoniae de hospitales de Bogotá, D.C., Colombia. Biomédica. 2011;31:15-20. https://doi.org/10.7705/biomedica.v31i1.331

38. Gaitán S, Espinal P, Grupo de Investigación en Resistencia Bacteriana Región Caribe. Caracterización molecular de Escherichia coli y Klebsiella pneumoniae productores de $\beta$-lactamasas de espectro extendido en hospitales de la región Caribe, Colombia. Rev Chil Infect. 2009;26:239-246. https://doi.org/10.4067/S0716-10182009000400006

39. Mojica MF, Correa A, Vargas DA, Maya JJ, Montealegre MC, Rojas LJ, et al. Molecular correlates of the spread of KPC-producing Enterobacteriaceae in Colombia. Int J Antimicrob Agents. 2012;40:277-9. https://doi.org/10.1016/j.ijantimicag.2012.05.006

40. Martínez, P, Garzón D, Máttar S. CTX-M-producing Escherichia coli and Klebsiella pneumoniae isolated from community-acquired urinary tract infections in Valledupar, Colombia. Braz J Infect Dis. 2012;16:420-5. https://doi.org/10.1016/j.bjid.2012.05.001

41. Martínez P, Sánchez L, Máttar S. Carbapenemase KPC-2 in ESBL-producing Enterobacteriaceae from two clinics from Villavicencio, Colombia. Braz J Infect Dis. 2014;18:100-1. https://doi.org/10.1016/j.bjid.2013.09.002

42. García IA, Valenzuela EM, Saavedra CH, Leal AL, Eslava J, Mantilla JR. Caracterización molecular de aislamientos de Enterobacter cloacae multirresistentes, productores B-lactamasas provenientes de pacientes de un hospital de tercer nivel de Bogotá. Revista de la Facultad de Medicina de la Universidad Nacional de Colombia. 2005;53:148-59.

43. González E, Valenzuela E, Mantilla J, Leal A, Saavedra C, Eslava J. Resistencia a cefepime en aislamientos de Enterobacter cloacae provenientes de hospitales de Bogotá, Colombia. Rev Salud Pública. 2006;8:191-9. https://doi.org/10.1590/S0124-00642006000200007

44. Cuzon G, Naas T, Correa A, Quinn JP, Villegas MV, Nordmann P. Dissemination of the KPC2 carbapenemase in non-Klebsiella pneumoniae enterobacterial isolates from Colombia. Int J Antimicrob Agents. 2013;42:59-62. https://doi.org/10.1016/j.ijantimicag.2013.04.002

45. Paterson DL, Bonomo RA. Extended-spectrum $\beta$-Lactamases: A clinical update. Clin Microbiol Rev. 2005;18:657-86. https://doi.org/10.1128/CMR.18.4.657-686.2005

46. Bonnet R. Growing group of extended spectrum b-lactamases: The CTX-M enzymes. Antimicrob Agents Chemother. 2004;48:1-14. https://doi.org/10.1128/AAC.48.1.1-14.2004

47. Pitout JD, Laupland KB. Extended-spectrum beta-lactamase-producing Enterobacteriaceae: An emerging public-health concern. Lancet Infect Dis. 2008;8:159-66. https://doi.org/10.1016/S1473-3099(08)70041-0

48. Nicolas-Chanoine MH, Blanco J, Leflon-Guibout V, Demarty R, Alonso MP, Caniça MM, et al. Intercontinental emergence of Escherichia coli clone O25:H4-ST131 producing CTX-M-15. J Antimicrob Chemother. 2008;61:273-81. https://doi.org/10.1093/jac/dkm464 
49. Pfeifer $Y$, Cullik A, Witte W. Resistance to cephalosporins and carbapenems in Gramnegative bacterial pathogens. Int J Med Microbiol. 2010;300:371-9. https://doi.org/10.1016/j.ijmm.2010.04.005

50. Rasmussen JW, Hoiby N. Cefotaximases (CTX-M-ases), an expanding family of extendedspectrum beta-lactamases. Can J Microbiol. 2004; 50:137-65. https://doi.org/10.1139/w03-111

51. Radice M, Power P, Di Conza J, Gutkind G. Early dissemination of CTX-M-derived enzymes in South America. Antimicrob Agents Chemother. 2002;46:602-4. https://doi.org/10.1128/AAC.46.2.602-604.2002

52. Villegas MV, Correa A, Pérez F, Zuluaga T, Radice M, Gutkind G, et al. CTX-M-12 $\beta$-lactamase in a Klebsiella pneumoniae clinical isolate in Colombia. Antimicrob Agents Chemother. 2004;48:629-31. https://doi.org/10.1128/AAC.48.2.629-631.2004

53. Mantilla JR, Reguero MT, González E, García I, Leal A, Espinal P, et al. Caracterización molecular de un brote por Klebsiella pneumoniae productora de CTX-M-12 en la unidad de cuidado intensivo neonatal de un hospital colombiano. Biomédica. 2006;26:408-14. https://doi.org/10.7705/biomedica.v26i3.359

54. Valenzuela EM, Mantilla JR, Reguero MT, González EB, Pulido IY, Llerena ID, et al. Detection of CTX-M-1, CTX-M-15, and CTX-M-2 in clinical isolates of Enterobacteriaceae in Bogotá, Colombia. J Clin Microbiol. 2006;44:1919-20. https://doi.org/10.1128/JCM.44.5.1919-1920.2006

55. Celis Y, Pulido I, Valenzuela-de Silva E, Reguero M, Mantilla J. Ambiente genético del gen blaCTX-M-12 en aislamientos hospitalarios de Klebsiella pneumoniae. Rev Colomb Biotecnol. 2009;11:48-58.

56. Mantilla JR, Barreto E, Reguero MT, Velandia DA. Identifying cefotaximase genes in Enterobacteriaceae hospital isolates by PCR-SSCP. Rev Colomb Biotecnol. 2009;11:57-65.

57. Ruiz SJ, Montealegre MC, Ruiz-Garbajosa P, Correa A, Briceño DF, Martínez E, et al. First characterization of CTX-M-15-producing Escherichia coli ST131 and ST405 clones causing community-onset infections in South America. J Clin Microbiol. 2011;49:1993-6. https://doi.org/10.1128/JCM.00045-11

58. González LM, Pérez-Díaz JC, Ayala J, Casellas JM, Martínez-Beltrán J, Bush K, et al. Gene sequence and biochemical characterization of FOX-1 from Klebsiella pneumoniae, a new AmpC-type plasmid-mediated beta-lactamase with two molecular variants. Antimicrob Agents Chemother. 1994;38:2150-7. https://doi.org/10.1128/AAC.38.9.2150

59. Rapoport M, Monzani V, Pasteran F, Morvay L, Faccone D, Petroni A, et al. CMY- 2-type plasmid-mediated AmpC beta-lactamase finally emerging in Argentina. Int J Antimicrob Agents. 2008;31:385-7. https://doi.org/10.1016/j.ijantimicag.2007.11.016

60. Leal AL, Cortés JA, Arias G, Ovalle MV, Saavedra SY, Buitrago G, et al. Emergence of resistance to third generation cephalosporins by Enterobacteriaceae causing communityonset urinary tract infections in hospitals in Colombia. Enferm Infecc Microbiol Clin. 2013;31:298-303. https://doi.org/10.1016/j.eimc.2012.04.007

61. Queenan AM, Bush K. Carbapenemases: The versatile beta-lactamases. Clin Microbiol Rev. 2007;20:440-58. https://doi.org/10.1128/CMR.00001-07

62. Patel G, Huprikar S, Factor SH, Jenkins SG, Calfee DP. Outcomes of carbapenem-resistant Klebsiella pneumoniae infection and the impact of antimicrobial and adjunctive therapies. Infect Control Hosp Epidemiol. 2008;29:1099-106. https://doi.org/10.1086/592412

63. Marchaim D, Chopra T, Pérez F, Hayakawa K, Lephart PR, Bheemreddy S, et al. Outcomes and genetic relatedness of carbapenem-resistant Enterobacteriaceae at Detroit medical center. Infect Control Hosp Epidemiol. 2011;32:861-71. https://doi.org/10.1086/661597

64. Nordmann P, Mariotte S, Naas T, Labia R, Nicolas MH. Biochemical properties of a carbapenem-hydrolyzing beta-lactamase from Enterobacter cloacae and cloning of the gene into Escherichia coli. Antimicrob Agents Chemother. 1993;37:939-46. https://doi.org/10.1128/AAC.37.5.939

65. Pottumarthy S, Moland ES, Juretschko S, Swanzy SR, Thomson KS, Fritsche TR. NmcA carbapenem-hydrolyzing enzyme in Enterobacter cloacae in North America. Emerg Infect Dis. 2003;9:999-1002. https://doi.org/10.3201/eid0908.030096

66. Deshpande LM, Jones RN, Fritsche TR, Sader HS. Occurrence and characterization of carbapenemase-producing Enterobacteriaceae: report from the SENTRY Antimicrobial Surveillance Program (2000-2004). Microb Drug Resist. 2006;12:223-30. https://doi.org/10.1089/mdr.2006.12.223 
67. Radice M, Power P, Gutkind G, Fernández K, Vay C, Famiglietti A, et al. First class A carbapenemase isolated from Enterobacteriaceae in Argentina. Antimicrob Agents Chemother. 2004;48:1068-9. https://doi.org/10.1128/AAC.48.3.1068-1069.2004

68. Osterblad M, Kirveskari J, Hakanen AJ, Tissari P, Vaara M, Jalava J. Carbapenemaseproducing Enterobacteriaceae in Finland: The first years (2008-11). J Antimicrob Chemother. 2012;67:2860-4. https://doi.org/10.1093/jac/dks299

69. Blanco VM, Rojas LJ, De La Cadena E, Maya JJ, Camargo RD, Correa A, et al. First report of a nonmetallocarbapenemase class A carbapenemase in an Enterobacter cloacae isolate from Colombia. Antimicrob Agents Chemother. 2013;57:3457. https://doi.org/10.1128/AAC.02425-12

70. Yigit H, Queenan AM, Anderson GJ, Domenech-Sánchez A, Biddle JW, Steward CD, et al. Novel carbapenem-hydrolyzing b-lactamase, KPC-1, from a carbapenem-resistant strain of Klebsiella pneumoniae. Antimicrob Agents Chemother. 2001;45:1151-61. https://doi.org/10.1128/AAC.45.4.1151-1161.2001

71. Nordmann P, Cuzon G, Naas T. The real threat of Klebsiella pneumoniae carbapenemaseproducing bacteria. Lancet Infect Dis. 2009;9:228-36. https://doi.org/10.1016/S1473-3099(09)70054-4

72. Villegas M, Lolans K, Correa A, Suárez JC, López JA, Vallejo M, et al. First detection of the plasmid-mediated class A carbapenemase KPC-2 in clinical isolates of Klebsiella pneumoniae from South America. Antimicrob Agents Chemother. 2006;50:2880-2. https://doi.org/10.1128/AAC.00186-06

73. Villegas MV, Lolans K, Correa A, Kattan JN, López JA, Quinn JP. First identification of Pseudomonas aeruginosa isolates producing a KPC-type carbapenem-hydrolyzing betalactamase. Antimicrob Agents Chemother. 2007;51:1553-5. https://doi.org/10.1128/AAC.01405-06

74. Naas T, Cuzon G, Villegas MV, Lartigue MF, Quinn JP, Nordmann P. Genetic structures at the origin of acquisition of the beta-lactamase bla KPC gene. Antimicrob Agents Chemother. 2008;52:1257-63. https://doi.org/10.1128/AAC.01451-07

75. Cuzon G, Naas T, Truong H, Villegas MV, Wisell KT, Carmeli Y, et al. Worldwide diversity of Klebsiella pneumoniae that produce beta-lactamase blaKPC-2 gene. Emerg Infect Dis. 2010;16:1349-56. https://doi.org/10.3201/eid1609.091389

76. Cuzon G, Naas T, Villegas MV, Correa A, Quinn JP, Nordmann P. Wide dissemination of Pseudomonas aeruginosa producing beta-lactamase blaKPC-2 gene in Colombia. Antimicrob Agents Chemother. 2011;55:5350-3. https://doi.org/10.1128/AAC.00297-11

77. Buelvas FA, Díaz MA, Muñoz AB, Tovar C. Aislamiento clínico de Pseudomonas aeruginosa productor de KPC-2 en la ciudad de Montería, Córdoba, Colombia. Infectio. 2013;17:35-8.

78. Pacheco R, Osorio L, Correa A, Villegas MV. Prevalencia de bacterias Gram negativas portadores del gen bla ${ }_{\mathrm{KPC}}$ en hospitales de Colombia. Biomédica. 2014;34(Supl.1):81-90. https://doi.org/10.7705/biomedica.v34i0.1642

79. Vanegas JM, Parra OL, Jiménez JN. Molecular epidemiology of carbapenem resistant gram-negative bacilli from infected pediatric population in tertiary - care hospitals in Medellín, Colombia: An increasing problem. BMC Infect Dis. 2016;16:463. https://doi.org/10.1186/s12879-016-1805-7

80. López JA, Correa A, Navon-Venezia S, Correa AL, Torres JA, Briceño DF, et al. Intercontinental spread from Israel to Colombia of a KPC-3-producing Klebsiella pneumoniae strain. Clin Microbiol Infect. 2011;17:52-6. https://doi.org/10.1111/j.1469-0691.2010.03209.x

81. Rodríguez E, Saavedra Y, Leal A, Álvarez C, Olarte N, Valderrama A, et al. Diseminación de Klebsiella pneumoniae productoras de KPC-3 en hospitales de Bogotá durante un periodo de tres años. Biomédica. 2014;34(Supl.1):224-31. https://doi.org/10.7705/biomedica.v34i0.1696

82. Ocampo AM, Vargas CA, Sierra P, Cienfuegos AV, Jiménez J. Caracterización molecular de un brote de Klebsiella pneumoniae resistente a carbapenémicos en un hospital de alto nivel de complejidad de Medellín, Colombia. Biomédica. 2015;35:496-504. https://doi.org/10.7705/biomedica.v35i4.2610

83. Ovalle MV, Saavedra SY, González MN, Hidalgo AM, Duarte C, Beltrán M. Resultados de la vigilancia nacional de la resistencia antimicrobiana de enterobacterias y bacilos Gram negativos no fermentadores en infecciones asociadas a la atención de salud, Colombia, 2012-2014. Biomédica. 2017;37:473-85. https://doi.org/10.7705/biomedica.v37i4.3432 
84. Ocampo AM, Chen L, Cienfuegos AV, Roncancio G, Chavda KD, Kreiswirth BN, et al. A two-year surveillance in five Colombian tertiary care hospitals reveals high frequency of non-CG258 clones of carbapenem-resistant Klebsiella pneumoniae with distinct clinical characteristics. Antimicrob Agents Chemother. 2016;60:332-42. https://doi.org/10.1128/AAC.01775-15

85. Watanabe $\mathrm{M}$, lyobe $\mathrm{S}$, Inoue $\mathrm{M}$, Mitsuhashi S. Transferable imipenem resistance in Pseudomonas aeruginosa. Antimicrob Agents Chemother. 1991;35:147-51. https://doi.org/10.1128/AAC.35.1.147

86. Osano E, Arakawa Y, Wacharotayankun R, Ohta M, Horii T, Ito H, et al. Molecular characterization of an enterobacterial metallo $\beta$-lactamase found in a clinical isolate of Serratia marcescens that shows imipenem resistance. Antimicrob Agents Chemother. 1994;38:71-8. https://doi.org/10.1128/AAC.38.1.71

87. Lincopan N, McCulloch JA, Reinert C, Cassettari VC, Gales AC, Mamizuka EM. First isolation of metallo- $\beta$-lactamase-producing multiresistant Klebsiella pneumoniae from a patient in Brazil. J Clin Microbiol. 2005;43:516-9. https://doi.org/10.1128/JCM.43.1.516-519.2005

88. Lauretti L, Riccio ML, Mazzariol A, Cornaglia G, Amicosante G, Fontana R, et al. Cloning and characterization of blaVIM, a new integron-borne metallo-beta-lactamase gene from a Pseudomonas aeruginosa clinical isolate. Antimicrob Agents Chemother. 1999;43:1584-90. https://doi.org/10.1128/AAC.43.7.1584

89. Walsh TR, Toleman MA, Poirel L, Nordmann P. Metallo-beta-lactamases: The quiet before the storm? Clin Microbiol Rev. 2005;18:306-25. https://doi.org/10.1128/CMR.18.2.306-325.2005

90. Crespo MP, Woodford N, Sinclair A, Kaufmann ME, Turton J, Glover J, et al. Outbreak of carbapenem-resistant Pseudomonas aeruginosa producing VIM-8, a novel metallo-betalactamase, in a tertiary care center in Cali, Colombia. J Clin Microbiol. 2004;42:5094-101. https://doi.org/10.1128/JCM.42.11.5094-5101.2004

91. Montealegre MC, Correa A, Briceño DF, Rosas NC, De La Cadena E, Ruiz SJ, et al. Novel VIM metallo-beta-lactamase variant, VIM-24, from a Klebsiella pneumoniae isolate from Colombia. Antimicrob Agents Chemother. 2011;55:2428-30. https://doi.org/10.1128/AAC.01208-10

92. Correa A, Montealegre MC, Mojica MF, Maya JJ, Rojas LJ, De La Cadena EP, et al. First report of a Pseudomonas aeruginosa isolate coharboring KPC and VIM carbapenemases. Antimicrob Agents Chemother. 2012;56:5422-3. https://doi.org/10.1128/AAC.00695-12

93. Correa A, Del Campo R, Perenguez M, Blanco VM, Rodríguez-Baños M, Perez F, et al. Dissemination of high-risk clones of extensively drug-resistant Pseudomonas aeruginosa in Colombia. Antimicrob Agents Chemother. 2015;59:2421-5. https://doi.org/10.1128/AAC.03926-14

94. Vanegas JM, Cienfuegos AV, Ocampo AM, López L, del Corral H, Roncancio G, et al. Similar frequencies of Pseudomonas aeruginosa isolates producing KPC and VIM carbapenemases in diverse genetic clones at tertiary-care hospitals in Medellín, Colombia. J Clin Microbiol. 2014;52:3978-86. https://doi.org/10.1128/JCM.01879-14

95. Yong D, Toleman MA, Giske CG, Cho HS, Sundman K, Lee K, et al. Characterization of a new metallo-beta-lactamase gene, bla(NDM-1), and a novel erythromycin esterase gene carried on a unique genetic structure in Klebsiella pneumoniae sequence type 14 from India. Antimicrob Agents Chemother. 2009;53:5046-54. https://doi.org/10.1128/AAC.00774-09

96. Dortet L, Poirel L, Nordmann P. Worldwide dissemination of the NDM-type carbapenemases in Gram-negative bacteria. Biomed Res Int. 2014;2014:249856. https://doi.org/10.1155/2014/249856

97. Nordmann P, Naas T, Poirel L. Global spread of carbapenemase-producing Enterobacteriaceae. Emerg Infect Dis. 2011;17:1791-8. https://doi.org/10.3201/eid1710.110655

98. Pasteran F, Albornoz E, Faccone D, Gómez S, Valenzuela C, Morales M, et al. Emergence of NDM-1-producing Klebsiella pneumoniae in Guatemala. J Antimicrob Chemother. 2012;67:1795-7. https://doi.org/10.1093/jac/dks101

99. Escobar-Pérez JA, Olarte-Escobar NM, Castro-Cardozo B, Valderrama-Márquez IA, Garzón-Aguilar MI, Martínez-de la Barrera L, et al. Outbreak of NDM-1-producing Klebsiella pneumoniae in a neonatal unit in Colombia. Antimicrob Agents Chemother. 2013;57:195760. https://doi.org/10.1128/AAC.01447-12 
100. Saavedra-Rojas SY, Duarte-Valderrama C, González-de Arias MN, Ovalle-Guerro MV. Emergence of Providencia rettgeri NDM-1 in two departments of Colombia, 2012-2013. Enferm Infecc Microbiol Clin. 2017;35:354-8. https://doi.org/10.1016/j.eimc.2015.05.011

101. Instituto Nacional de Salud. Circulación de carbapenemasas tipo Nueva Delhi metalobetalactamasa (NDM) en Colombia 2012-2014. Bogotá, D.C.: INS; 2014.

102. Correa C, Castro E, Salamanca D, Bustacara L, Lemos E. Escherichia coli productora de Nueva Delhi metalo-b-lactamasa en Colombia: reporte de caso. Infectio. 2016. https://doi.org/10.1016/j.infect.2016.05.002

103. Evans BA, Amyes SG. OXA $\beta$-Lactamases. Clin Microbiol Rev. 2014;27:241-63. https://doi.org/10.1128/CMR,00117-13

104. Paton R, Miles RS, Hood J, Amyes SG, Miles RS, Amyes SG. ARI 1: $\beta$-lactamase-mediated imipenem resistance in Acinetobacter baumannii. Int J Antimicrob Agents. 1993;2:81-7. https://doi.org/10.1016/0924-8579(93)90045-7

105. Donald HM, Scaife W, Amyes SG, Young HK. Sequence analysis of ARI-1, a novel OXA $\beta$-lactamase, responsible for imipenem resistance in Acinetobacter baumannii 6B92. Antimicrob Agents Chemother. 2000;44:196-9. https://doi.org/10.1128/AAC.44.1.196-199.2000

106. Brown S, Young HK, Amyes SG. Characterisation of OXA-51, a novel class D carbapenemase found in genetically unrelated clinical strains of Acinetobacter baumannii from Argentina. Clin Microbiol Infect. 2005;11:15-23. https://doi.org/10.1111/j.1469-0691.2004.01016.x

107. Pinzón JO, Mantilla JR, Valenzuela EM, Fernández F, Álvarez CA, Osorio E. Caracterización molecular de aislamientos de Acinetobacter baumannii provenientes de la unidad de quemados de un hospital de tercer nivel de Bogotá. Infectio. 2006;10:71-8.

108. Villegas MV, Kattan JN, Correa A, Lolans K, Guzmán AM, Woodford N, et al. Dissemination of Acinetobacter baumannii clones with OXA-23 carbapenemase in Colombian hospitals. Antimicrob Agents Chemother. 2007;51:2001-4. https://doi.org/10.1128/AAC.00226-07

109. Turton JF, Ward ME, Woodford N, Kaufmann ME, Pike R, Livermore DM, et al. The role of ISAba1 in expression of OXA carbapenemase genes in Acinetobacter baumannii. FEMS Microbiol Lett. 2006;258:72-7. https://doi.org/10.1111/j.1574-6968.2006.00195.x

110. Saavedra SY, Núñez JC, Pulido IY, González EN, Valenzuela EM, Reguero MT, et al. Characterisation of carbapenem-resistant Acinetobacter calcoaceticus--A. baumannii complex isolates in a third-level hospital in Bogotá, Colombia. Int J Antimicrob Agents. 2008;31:389-91. https://doi.org/10.1016/j.ijantimicag.2007.12.008

111. Martínez P, Máttar S. Imipenem-resistant Acinetobacter baumannii carrying the ISAba1bla $_{\text {OXA-23.51 }}$ and ISAba1-bla ADC-7 genes in Monteria, Colombia. Braz J Microbiol. 2012;43:1274-80. https://doi.org/10.1590/S1517-83822012000400006

112. Hernández-Gómez C, Blanco VM, Motoa G, Correa A, Maya JJ, de la Cadena E, et al. Evolución de la resistencia antimicrobiana en bacilos Gram negativos en unidades de cuidados intensivos en Colombia. Biomédica. 2014;34(Supl.1):91-100. https://doi.org/10.7705/biomedica.v34i0.1667

113. Reguero MT, Medina OE, Hernández MA, Flórez DV, Valenzuela EM, Mantilla JR. Antibiotic resistance patterns of Acinetobacter calcoaceticus- $A$. baumannii complex species from Colombian hospitals. Enferm Infecc Microbiol Clin. 2013;31:142-6. https://doi.org/10.1016/j.eimc.2012.07.013

114. Montealegre MC, Maya JJ, Correa A, Espinal P, Mojica MF, Ruiz SJ, et al. First identification of OXA-72 carbapenemase from Acinetobacter pittii in Colombia. Antimicrob Agents Chemother. 2012;56:3996-8. https://doi.org/10.1128/AAC.05628-11

115. Saavedra SY, Cayô R, Gales AC, Leal AL, Saavedra CH. Early dissemination of OXA-72producing Acinetobacter baumannii strain in Colombia: A case report. Braz J Infect Dis. 2014;18:678-80. https://doi.org/10.1016/j.bjid.2014.05.017

116. Poirel L, Potron A, Nordmann P. OXA-48-like carbapenemases: The phantom menace. J Antimicrob Chemother. 2012;67:1597-606. https://doi.org/10.1093/jac/dks121

117. Vanegas JM, Ospina WP, Felipe Higuita-Gutiérrez L, Natalia Jiménez J. First reported case of an OXA-48-producing isolate from a Colombian patient. J Glob Antimicrob Resist. 2016;6:67-8. https://doi.org/10.1016/j.jgar.2016.04.001 